\title{
Musicians noise exposure in a Portuguese orchestra - a case study
}

\author{
Matilde A. Rodrigues ${ }^{1}$; Pedro Alves ${ }^{1}$; Luis Ferreira ${ }^{1}$; Paula Neves ${ }^{1}$; Livia Aguiar $^{2}$; Manuela Silva ${ }^{1}$ \\ ${ }^{1}$ ESTSP, Portugal \\ ${ }^{2}$ Instituto Nacional de Saúde Ricardo Jorge, Portugal
}

\section{INTRODUCTION}

Exposure to high noise levels is broadly recognized as being one of the most significant and frequent risk factors in occupational environments, particularly at industrial settings (Arezes et al., 2012). Such exposure can result in several effects for the workers' health, mainly in the development of noise-induced hearing loss (NIHL), which is the most frequent occupational disease in Europe (EU-OSHA, 2002). However, there are other professionals groups that are also considered as important, concerning noise exposure. The professional orchestras musicians are one of these groups. Previous studies show that orchestral musicians are exposed to loud music (Lee et al., 2005; MacDonald et al., 2008; O'Brien et al., 2008), which can have a great impact on their health. However, despite the relevance of this issue for orchestral musicians, it seems that the problematic of noise exposure is still not well characterized, and the strategy for the noise exposure assessment not well established. Furthermore, the Portuguese legislation, in particular the DecretoLei $\mathrm{n}^{\circ} 182 / 2006$, does not consider the specific case of musicians, and there is no code of conduct provided in accordance with Directive 2003/10/CE that establishes the guidelines about how musicians should be protected from noise exposure. This is particularly critical considering that the hearing ability of these musicians is a relevant part and a crucial tool of their professional activity and performance (Jansen et al., 2009; Kähäri et al., 2004). Besides, without a reliable risk assessment of musicians' exposure, it is not possible to compare sound pressure levels with the current guidelines and it is also very complex to define and implement an effective strategy to reduce the risk of NIHL (Arezes et al., 2012).

Faced to this problematic, and the lack of any characterization of noise exposure level for Portuguese orchestral musicians, this study aims to be a first attempt to characterize the noise level of exposition of Portuguese orchestral musicians, through a case study.

\section{MATERIALS AND METHOD}

Sound level measurements were made in musicians of one Portuguese orchestra. Two different repertoires during group rehearsals and general rehearsals were assessed.

\subsection{Instrument}

Measurements were performed using dosimeters and a sound level meter. Two Quest NoisePro dosimeters were used to

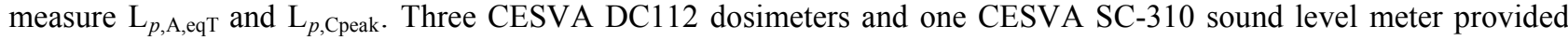
$\mathrm{L}_{p, \mathrm{~A}, \mathrm{eqT}}, \mathrm{L}_{p, \text { Cpeak }}$ and octaves frequency data.

After the field measurements, the data were transferred to the Capture Studio Editor Software and QuestSuite ${ }^{\mathrm{TM}}$ Professional Software, which processes all the data collected.

\subsection{Measurement procedure}

Before starting the study, its aim and procedures were explained to all musicians. Based on information delivered by the orchestra manager, test subjects were selected in accordance with their instrument and position in orchestra. In each rehearsal 10 musicians were evaluated, as well as the conductor at the same time. In order to analyse the variation among rehearsals in the same repertoire, 7 of the assessed musicians were the same. The others were different in order to include as many situations as possible. Between both repertoires 6 musicians were the same.

Participants were requested to wear noise dosimeters during the entire rehearsals. The microphone was located on the left or right shoulder of the test subject, close to the most exposed ear, without restricting movement. In the case of string instruments, the microphone was positioned on the opposite shoulder of the instrument. A sound meter was used to analyse the conductor exposition, and the equipment was fixed on the support up to the height of the conductor ear.

\subsection{Results treatment}

According to the Portuguese legislation, Decreto-Lei $n^{\circ} 182 / 2006$, it is only possible to determine the level of daily exposure or weekly average exposure. Consequently, the average sound level for a year, as presented in previous works, is beyond the scope of Portuguese legislation. Therefore, exposure level normalized to a n ominal week of five $8 \mathrm{~h}$ working days was determined, considering all time that musicians' spend with the orchestra. In accordance with the ISO 9612:2009, a $\mathrm{L}_{p, \mathrm{~A}, \mathrm{eqT}}=70 \mathrm{~dB}$ was used to the remaining periods as a conservative estimate.

\section{RESULTS AND DISCUSSION}

The orchestra was divided into six groups: strings, woodwinds, brass, percussion and timpani, piano and conductor. Strings includes violin I and II, viola, cello and contrabass. Woodwinds comprise bassoon, saxophone, flute, clarinet, oboe, recorder and piccolo. Brass includes trombone, tuba, trumpet and French horn. 
For each repertoire, values of $\mathrm{L}_{p, \mathrm{~A} \text {,eq }}$ and $\mathrm{L}_{p \text {, Cpeak }}$ were measure and are presented in Table 1 and Table 2 . As the rehearsals of each repertoire were carried out over one week, it was determined the weekly average exposure for each repertoire and are also presented in Table 1 and Table $2\left(\bar{L}_{\mathrm{EX}, 8 \mathrm{~h}}\right)$.

Table 1 - Summary of data by group of instrument type in repertoire A

\begin{tabular}{|c|c|c|c|c|c|c|c|}
\hline & \multicolumn{2}{|c|}{ Group Rehearsal 1} & \multicolumn{2}{|c|}{ Group Rehearsal 2} & \multicolumn{2}{|c|}{ General rehearsal } & \multirow[b]{2}{*}{$\begin{array}{l}L_{\mathrm{EX}, 8 \mathrm{~h}} \\
\mathrm{~dB}(\mathrm{~A})\end{array}$} \\
\hline & $\begin{array}{l}L_{p, A, e q T} \\
\text { dB (A) }\end{array}$ & $\begin{array}{c}L_{p, \text { Cpeak }} \\
\text { dB (C) }\end{array}$ & $\begin{array}{l}\mathbf{L}_{p, A, e q T} \\
\text { dB (A) }\end{array}$ & $\begin{array}{c}\mathbf{L}_{p, \text { Cpeak }} \\
\text { dB (C) }\end{array}$ & $\begin{array}{c}\mathbf{L}_{p, \mathrm{~A}, \mathrm{eqT}} \\
\mathbf{d B} \text { (A) }\end{array}$ & $\begin{array}{c}\mathbf{L}_{p, \text { Cpeak }} \\
\text { dB (C) }\end{array}$ & \\
\hline Strings & $81.8-88.7$ & $114.7-124.0$ & $81.9-89.7$ & $115.9-128.9$ & $83.1-91.9$ & $115.1-117.3$ & $77.1-84.1$ \\
\hline Woodwinds & $89.3-92.8$ & $119.3-122.2$ & $87.6-96.8$ & $115.4-123.2$ & --- & --- & $83.1-89.2$ \\
\hline Brass & $90.0-92.6$ & $128.2-126.5$ & $90.4-92.7$ & 122.6 & $87.7-91.9$ & 118.6 & $84-86.5$ \\
\hline Timpani & 88,6 & 128,8 & 90,8 & 130,4 & 92,8 & 130,5 & 84,8 \\
\hline Conductor & 80,6 & 110,7 & 81,9 & 107,7 & 82,9 & 111,8 & 76,1 \\
\hline
\end{tabular}

Table 2 - Summary of data by group of instrument type in repertoire B

\begin{tabular}{|c|c|c|c|c|c|c|c|}
\hline & \multicolumn{2}{|c|}{ Group Rehearsal 1} & \multicolumn{2}{|c|}{ Group Rehearsal 2} & \multicolumn{2}{|c|}{ General rehearsal } & \multirow[b]{2}{*}{$\begin{array}{l}L_{\mathrm{EX}, 8 \mathrm{~h}} \\
\mathrm{~dB}(\mathrm{~A})\end{array}$} \\
\hline & $\begin{array}{c}\mathbf{L}_{p, \mathrm{~A}, \mathrm{eqT}} \\
\mathrm{dB} \text { (A) }\end{array}$ & $\begin{array}{c}\mathbf{L}_{p, \text { Cpeak }} \\
\text { dB (C) }\end{array}$ & $\begin{array}{c}\mathbf{L}_{p, \mathrm{~A}, \mathrm{eqT}} \\
\mathrm{dB} \text { (A) }\end{array}$ & $\begin{array}{c}\mathbf{L}_{p, \text { Cpeak }} \\
\text { dB (C) }\end{array}$ & $\begin{array}{c}\mathbf{L}_{p, \mathrm{~A}, \mathrm{eqT}} \\
\mathbf{d B} \text { (A) }\end{array}$ & $\begin{array}{c}\mathbf{L}_{p, \text { Cpeak }} \\
\text { dB (C) }\end{array}$ & \\
\hline Strings & $88.7-89.4$ & $117.8-123.9$ & $88.7-89.3$ & $120.6-120.8$ & $88.3-89.4$ & $117.8-120.7$ & $81.8-82.3$ \\
\hline Woodwinds & $91.5-92.8$ & $133.9-134.0$ & 93.4 & 125.6 & 92 & 121.6 & $85.3-85.8$ \\
\hline Brass & $92,6-95.1$ & $123,2-132.3$ & 93,2 & 134,4 & 94,2 & 133,7 & 86 \\
\hline Percussion & 92,2 & 133,9 & 95,4 & 136,5 & --- & --- & 87 \\
\hline Piano & 86,2 & 132,7 & --- & --- & 84,8 & 116,4 & 78,9 \\
\hline Conductor & 84,4 & 115,1 & 84,2 & 116,4 & 84,3 & 115,6 & 77,9 \\
\hline
\end{tabular}

The results indicate that Portuguese orchestral musicians are exposed to high sound levels in the course of rehearsals, in the same way of previous studies (Lee et al., 2005; MacDonald et al., 2008; O'Brien et al., 2008). Values of $\mathrm{L}_{p, \mathrm{~A}, \text { eqT }}$ vary in accordance with the instruments type, where noise levels were found, in general, higher for brass and lower for conductor, conductor, being the results found by Lee et al. (2005) and O'Brien et al. (2008) similar with this study. Furthermore, $\mathrm{L}_{p, \mathrm{~A} \text {,eqT }}$ values vary with the repertoire. These results can be related with differences in the programme, in the number of musicians and in the type of instruments included. The $\mathrm{L}_{p \text {,Cpeak }}$ achieve the lower exposure action level presented in Decreto-Lei $\mathrm{n}^{\mathrm{o}} 182 / 2006$ [135 $\left.\mathrm{dB}(\mathrm{C})\right]$ for percussion in repertoire $\mathrm{B}$. The $\bar{L}_{\mathrm{EX}, 8 \mathrm{~h}}$ for all instrument groups of the orchestra exceeded the lower exposure action level presented in Decreto-Lei $\mathrm{n}^{\mathrm{o}} 182 / 2006$, i.e., $80 \mathrm{~dB}(\mathrm{~A})$, except for the conductor and piano. Beside that, the higher exposure action level, $85 \mathrm{~dB}(\mathrm{~A})$, was exceeded by brass, woodwinds and percussion. These results show that musicians are at risk of NIHL.

\section{CONCLUSIONS}

The results obtained in this study showed that the orchestral musicians are exposed to high sound levels in the course of the rehearsals and it was dependent of instrument type, repertoire and position, indicating that more attention need to be provided to these professionals. This study is still in course, including more exposure sources in order to determine with more accuracy their levels of exposure, as well as, to compare their individual levels of exposure with the current guidelines.

\section{REFERENCES}

Arezes, P.M., Bernardo, C.A. \& Mateus O.A. (2012). Measurement strategies for occupational noise exposure assessment: A comparison study in different industrial environments. International Journal of Industrial Ergonomics, 42 (1), $172-177$.

Decreto-Lei n. ${ }^{\circ}$ 182/2006 de 6 de Setembro. Diário da República nº $172-1^{a}$ Série. Lisboa.

Directive 2003/10/EC, of the European Parliament and of the Council, of 6 February 2003.

EU-OSHA. (2002). Data to describe the link between OSH and employability. European Agency for Safety and Health at Work. ISBN 92-95007-66-2.

ISO 9612:2009. Acoustics - Determination of occupational noise exposure - Engineering method. International Organization for Standard.

Jansen, E. J. M., Helleman, H. W., Dreschler, W. A. \& de Laat, J. A. P. M. (2009). International Archives of Occupational and Environmental Health, 82, 153-164.

Kähäri, K., Zachau, G., Eklöf, M. \& Möllerc, C. (2004) The influence of music and stress on musicians' hearing. Journal of Sound and Vibration, 277, 627-631.

MacDonald, E. N., Behar, A., Wong, W. \& Kunov, H. (2008). Noise exposure of opera musicians. Canadian Acoustics, 36 (4), 11-16.

Lee, J., Behar, A., Kunov, H. \& Wong W. (2005). Musicians noise exposure in orchestra pit. Applied Acoustics, 66, 919-93.

O’Brien, I., Wilson, W. \& Bradley, A. (2008). Nature of orchestral noise. Acoustical Society of America, 124 (2), 926-939. 